\title{
Root- Nodulating Ensifer Adhaerens Ks23 of Pisum Sativum L. In Optimisation of Cadmium Biosorption Using Rsm Based Approach
}

prashant katiyar ( $\sim$ prashant22021994@gmail.com )

Gurukula Kangri University: Gurukula Kangri vishwavidyalaya https://orcid.org/0000-0002-6355-687X

\section{Sandeep Kumar}

Gurukula Kangri University: Gurukula Kangri vishwavidyalaya

Ramesh Chandra Dubey

Gurukula Kangri University: Gurukula Kangri vishwavidyalaya

Dinesh Kumar Maheshwari

Gurukula Kangri University: Gurukula Kangri vishwavidyalaya

\section{Research Article}

Keywords: ACC-deaminase, Biosorption, Heavy metals, Ensifer, RSM, Toxicity

Posted Date: May 17th, 2021

DOI: https://doi.org/10.21203/rs.3.rs-482431/v1

License: @ (i) This work is licensed under a Creative Commons Attribution 4.0 International License. Read Full License 


\section{Abstract}

The Cadmium tolerance by root nodulating bacteria Ensifer adhaerens KS23 inhabiting in Pisum sativum L. var. Arkel revealed linear relationship with inorganic salt cadmium sulphate $\left(\mathrm{CdSO}_{4}\right)$ upto $200 \mu \mathrm{g} / \mathrm{ml}$, corresponding to growth and survival in solid as well as liquid Yeast Extract Mannitol (YEM) medium with LC50 value of $107.2 \mu \mathrm{g} / \mathrm{ml}$ and LC95 of $184.5 \mu \mathrm{g} / \mathrm{ml}$. The results of phylogenetic and morpho-physiological analysis exhibited the genus E. adhaerens. KS23 was found to be the most promising among all the 20 isolates. The increase in Glutathione S-transferase (GST) activity by KS23 was 9.7 fold under Cd stress. Wherein, $P$ and $F$ values were $<0.05$ and 26.54 respectively and predicted $r^{2}$ value of 0.8192 and adjusted $r^{2}$ value 0.8908 were reasonable (i.e. <0.2) of the Box Behnken design. The data showed that $81.24 \%$ cadmium bio-removal achieved at $\mathrm{pH} 6.0,30^{\circ} \mathrm{C}$ and $168 \mathrm{~h}$ of incubation while supplementing the YEM medium with $25 \mu \mathrm{g} / \mathrm{ml}$ cadmium. Further, its effect on plant growth and development exhibited due to production of IAA, secretion of siderophores, phosphate solubilisation and 1-aminocyclopropane-1-carboxylic acid (ACC) deaminase activity by E. adhaerens KS23. In addition to inherent PGP attributes, Cd tolerant $E$. adhaerens KS23 played dual role of biosorption of cadmium and upsurge in growth promotion of $P$. sativum which may provide a new root-nodulating bacterium inhabiting in $P$. sativum cultivated at high altitudes of Himalayan region.

\section{Introduction}

Due to the fact that biostimulation, bio fertilization, biocontrol and sometimes by biosorption are multitask phenomenon and in this scenario, bacteria of a group of PGPR impart tolerance to biotic and abiotic stresses including heavy metals. Cadmium (Chi et al., 2020; Wang et al., 2020), Klebsiella pneumoniae and Citrobacter freundii for lead exhibited their potential in promoting the plant growth in heavy metals contaminated soil (Al-Garni, 2005). Soil can be contaminated by many polluting sources, such as composts, pesticides, emissions from municipal waste sites, metal smelting industry, etc. and leached out several heavy metals such as zinc (Zn), cadmium (Cd), lead (Pb) and copper (Cu) (Stylianou et al., 2007). Soil acts both as a reservoir as well as temporary storage of metal-ions, therefore, the heavy metals estimation is utmost important. Few root nodulating bacteria inhabiting in legumes observed in bioremediation and biosorption of cadmium and other heavy metals and pesticides (Sathvika et al., 2018; Edulamudi et al., 2019). The available literature revealed that inspite of its broad ecological niche (Katiyar et al., 2021), investigations on biosorption potential of cadmium by rootnodulating Ensifer adhaerens, even at low concentrations of Cd caused significant harm to the food chain ecosystem (Li et al., 2018). However, other alternatives for their removal such as biosorbents by living or dead biomass, agricultural waste or industrial byproducts, are other options (Wang et al., 2009). The physiochemical degradation of these heavy metal pollutants is a cumbersome and onerous affair and also not eco-friendly. Root colonizing bacteria have the capacity to accumulate further amounts of metal in the host plant roots and limit the entry of it to other parts of the plant (Nagata et al., 2015). It is therefore, the removal of heavy metls by microbes has gained a great deal of interest.

Response Surface Methodology (RSM) is commonly used in rhizosphere bio-engineering the biosorption of iron, lead and cadmium to newly isolated bacteria using a Box-Behnken design (Choińska-Pulit et al., 2018). The root-nodulating bacteria procured from standing crop of Pisum sativum L. var. Arkel cultivated in field soil contaminated with heavy metals with cadmium as dominant contaminant of soil. The plant growth promotion attributes such as IAA, siderophore, HCN production, production of ACC- deaminase and assessment of heavy metal (Cd II) biosorption (Zhang and Shu, 2006) by the selected bacterial isolates and determination of Glutathione S-tranferase activity and optimization of variables, such as $\mathrm{pH}$, temperature, initial concentration, these parameters have been aimed for maximum biosoprtion (Actual Removal Efficiency) of Cadmium (Cd) and their removal in farmer's field soil.

\section{Materials And Methods}

\section{Procurement of root-nodulating bacteria and culture conditions}

The root nodulating bacterial isolates KS09, KS23 and KR16 were procured from Department of Microbiology, Grukul Kangri (Deemed to be University), Haridwar- 249404 Uttarakhand (India). The isolates were obtained from our previous study (Katiyar et al., 2021) and maintained on Yeast Extract Mannitol Agar supplemented with congo red (crYEMA) medium at $4{ }^{\circ} \mathrm{C}$ as described by Dubey and Maheshwari, (2012).

\section{Enrichment and effect of cadmium concentration}

The cadmium-bacteria mixed culture was centrifuged at $3500 \times \mathbf{g}$ for $5 \mathrm{~min}$, and the supernatant was collected in a clean tube and

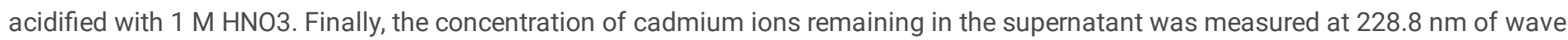


length using a UV-Vis spectrophotometer (Shimadzu-1601) in triplicates. The cadmium removal efficiency was calculated by the following equations:

$$
R=\frac{C o-C e}{C o} \times 100 \%
$$

where $C o$ and $C e$ was the initial concentrations and equilibrium concentration of cadmium (mg/l), respectively.

\section{Physio- chemical soil analysis}

Atomic Absorption Spectrometry (Thermo fisher iCE 3300 AAS) was used in determining the content of heavy metals in the previously digested soil samples from pre-sowing and post-harvest soil of farmer's field (Srinagar, Garhwal, India). The nitrous oxide, acetylene gas, and compressor were all fixed, and the compressor was turned on, with the liquid trap blown to remove any trapped liquid. The AAS control and the extractor were both turned on. Purifying wire was used to clean the slender tube and nebulizer piece, and an arrangement card was used to clean the burner opening. The light was switched on and the cathode beam was changed to hit the arrangement card's goal zone. The fine was positioned in a $10 \mathrm{ml}$ graduated chamber filled with deionized water and the rate of yearning was calculated. Based on the absorbance obtained for the unknown sample, the different metal concentrations in the sample solution were calculated from the calibration as given by Radu and Diamond (2009).

\section{Effects of treatments on vegetative parameters}

The isolates KS09, KS23 and KR16 were selected for seed bacterization (Weller and Cook, 1983). Healthy seeds of $P$. sativum var. Arkel were washed with distilled water and air-dried. The seeds were then sown in earthen pots of six inches height and eight inches diameter. The four treatments were given, Control: sterile seeds; T1: seeds + KS09; T2: seeds + KS23; T3: seeds+ KR16. After thirty days of sowing (30 DAS), early vegetative parameters such as root/shoot length and fresh and dry weight of root/shoot were recorded.

\section{Glutathione S-transferase activity (GST)}

The estimation of GST produced was determined as given by Habig et al. (1974). The sample was homogenised in phosphate buffer (pH 6.5 @ $100 \mathrm{mM}$ ) and centrifuged at 9,000 g for 30 minutes. The absorbance was measured at $340 \mathrm{~nm}$ (Shimadzu UV-Vis 1601 , Japan) wave length. It was measured by monitoring the reduction of GSH concentration at 412 nm after ts reaction with 1-chloro-2, 4dinitrobenzene (CDNB): $\mathrm{GSH}+\mathrm{C}_{6} \mathrm{H}_{3}\left(\mathrm{NO}_{2}\right)_{2} \mathrm{Cl}(\mathrm{CDNB}) \rightarrow \mathrm{C}_{6} \mathrm{H}_{3}\left(\mathrm{NO}_{2}\right)_{2} \mathrm{GS}+\mathrm{H}^{+}+\mathrm{Cl}^{-}$. $\mathrm{U}$ is defined as a unit of enzymatic activity, which reduces $1.0 \mu \mathrm{mol} / 1000 \mathrm{ml} \mathrm{GSH}$ per mg protein in one minute at $37^{\circ} \mathrm{C}$, after subtracting non-enzymatic reaction. The protein was quantified by the Coomassie blue colorimetric assay using bovine serum albumin as the standard. Concentration of glutathione $\mathrm{S}$ transferase was expressed in units/ml protein.

\section{Designing of experiment for biosorption studies}

A set of $150 \mathrm{ml}$ Erlenmeyer flasks were used in the single factor test, which contained $50 \mathrm{ml}$ of Yeast mannitol Broth with different metal concentrations. The effects of contact time (12-144 h), $\mathrm{pH}$ (2-10), temperature $\left(15-40{ }^{\circ} \mathrm{C}\right)$, biomass dosage $(0.002-0.016 \mathrm{~g})$ and initial cadmium concentration $(5-100 \mu \mathrm{g} / \mathrm{ml})$ on the removal efficiency of cadmium were studied (Wang et al., 2014; Qasemi et al., 2018). The bacteria were harvested after respective time of culturing at different parameters for subsequent experiments.

\section{Optimization of biosorption conditions}

In order to accurately predict the optimum biosorption conditions for $\mathrm{Cd}$ by isolate $\mathrm{KS} 23$ and minimize the number of experiments, the Box-Behnken design (BBD) based on RSM was designed. The RSM consists of a set of experimental methods designed to the evaluation of correlation between a number of controlled experimental factors and obtained responses according to one or more selected criteria. Contact time (A), $\mathrm{pH}(\mathrm{B})$, and initial cadmium concentration (C) were screened as key factors affecting removal efficiency and the appropriate range of independent variables was determined. According to the BBD (Design Expert software, V.13.0, 2020) (Raymond and Montgomery, 2009), three levels and three factors were employed to determine the optimal biosorption variables to improve biosorption efficiency.

\section{Results}


On subjecting the selected isolate to molecular identification using 16S rRNA gene sequencing, the data revealed the strains to be Rhizobium leguminosarum KS09 (MW575402), Ensifer adhaerens KS23 (MW019954) and Rhizobium phaseoli KR16 (MW621971). A phylogenetic tree was constructed for each strain by using MEGA X (Kumar et al., 2018) (Supplementary Figure S1, S2 and S3).

\section{Enrichment and effect of cadmium on isolates}

After 7 days of incubation, the isolate was supplemented with varying concentrations of $\mathrm{CdSO}_{4}$ at $28{ }^{\circ} \mathrm{C}$. Minimum inhibitory concentrations (MIC) of $E$. adhaerens KS23 was calculated using probit analysis. The probit analysis revealed that LC50 value of KS23

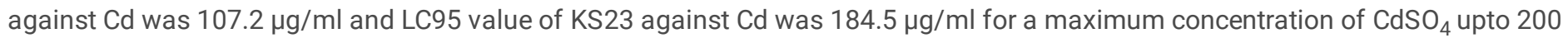
$\mu \mathrm{g} / \mathrm{ml}$ (Figure 1).

\section{Physio-chemical soil analysis}

Pre-sowing Soil analysis revealed that $\mathrm{Cd}$ and $\mathrm{Mn}$ present in the soil sample were significantly maximum in concentration in comparison to that of $\mathrm{Cu}, \mathrm{Cr}$ and $\mathrm{Pb}$, which were present in lower concentration (\%) than that of $\mathrm{Cd}$ and $\mathrm{Mn}$. $\mathrm{Cd}$ and $\mathrm{Ni}$ were present in amounts within the permissible limits (Table 1). However, there was a significant reduction in the concentration especially of Cd (II) which was well above permissible limit of $0.8 \mathrm{mg} / \mathrm{kg}$ (Saha et al., 2010). There is a decrease in cadmium concentration statistically from $4.84 \mu \mathrm{g} / \mathrm{kg}$ to $1.62 \mu \mathrm{g} / \mathrm{kg}$, which provides evidence of Cd biosorption by isolate $E$. adhaerens KS23 and thus improved the quality of soil.

\section{Effects of treatments on vegetative parameters}

After thirty days of sowing the seeds with different treatments, the treatment T2 (seeds + KS23) was found to be significant ( $p>0.05)$ in achieving effective enhancement in root/shoot length as well root/shoot fresh and dry weight. T2 showed a maximum increase of 34.83 $\%$ in root length, a $37.67 \%$ increment in shoot length over control. Similarly, T2 also enhanced root fresh weight (34\%), shoot fresh weight (37\%), root dry weight (24\%) and shoot dry weight (33\%) over controls respectively. This shows that E. adhaerens KS23 is capable of enhancing plant productivity effectively (Figure 2 a-c).

\section{Glutathione S-transferase (GST) activity}

For the lowest concentration of Cd used in the previous tests, the GST activity was determined (Figure 3). It is well understood that as the concentration of Cd (II) rises, corresponding to the activity of GST, but on further incubation of $144 \mathrm{~h}$, the GST activity declined. $E$. adhaerens KS23 was the most effective showing the 9.7 fold increase in the GST activity, followed by KS9 and KR16 that caused 7.6 and 7.3- fold increase in GST activity $(p<0.05)$ (Figure 4).

\section{Effect of Temperature}

Under the above optimal conditions for maximum cadmium biosorption viz.-contact time- $116 \mathrm{~h}$, biomass dosage $0.01 \mathrm{~g} / 50 \mathrm{ml}$, cadmium initial concentration $25 \mu \mathrm{g} / \mathrm{ml}, \mathrm{pH} 6.0$ were observed (Table 2). Optimization of temperature $\left(15,20,25,30,40^{\circ} \mathrm{C}\right.$ ), the removal efficiency was investigated and it was revealed that the removal efficiency increased corresponding to increase in temperature was recorded and on further incubation, decrease in activity was recorded. Taking into account of removal efficiency of $81.24 \%$, the maximum removal efficiency occurred at $25^{\circ} \mathrm{C}$.

\section{Effect of intial pH}

The effect of $\mathrm{pH}(2,3,4,5,6,7,8,9$ and 10) determined, when the other experimental conditions were set as follows: contact time $120 \mathrm{~h}$, biomass dosage $0.01 \mathrm{~g}$, cadmium initial concentration $10 \mu \mathrm{g} / \mathrm{ml}$ and temperature $35^{\circ} \mathrm{C}$, cadmium adsorption by Ensifer adhaerens KS23. A slow increase in removal efficiency observed at lower $\mathrm{pH}$ but the removal efficiency linearly increased from $\mathrm{pH} 5$ to $\mathrm{pH} 6$. At pH 4 , the removal efficiency maximally observed to be $48.23 \%$. At low pH, the cell surface sites are closely linked to $\mathrm{H}^{+}$ions, which is unavailable for other cations. Based on the results, $\mathrm{pH} 6.0$ was applied for further investigations.

\section{Effect of initial cadmium concentration}

The initial cadmium concentration played an important role in the removal efficiency. At higher concentration of cadmium, bacterial growth declined from $125 \mu \mathrm{g} / \mathrm{ml}$ concentration to the complete inhibition at $200 \mu \mathrm{g} / \mathrm{ml}$. In this work, different initial cadmium concentration $5,10,25,40,60,80,100 \mu \mathrm{g} / \mathrm{ml}$ were prepared when other experimental parameters were performed as follows: contact 
time $120 \mathrm{~h}$, biomass dosage $0.012 \mathrm{~g}, \mathrm{pH} 6.0$, and temperature $25^{\circ} \mathrm{C}$. The removal efficiency reached the maximum of $81.24 \%$ at a concentration of $25 \mu \mathrm{g} / \mathrm{ml}$.

\section{Analysis of the Response Surface}

These plots could help to understand better, both main and interaction effects of variables, such as temperature and $\mathrm{pH}$ value on cadmium removal efficiency (Figure 5 [a-d]). At $25 \mu \mathrm{g} / \mathrm{ml}$, the removal efficiency of Cd (II) decreased from79 \% to $68 \%$ with the increasing initial $\mathrm{pH}$ from 5 to $\mathrm{pH} 7$, while the removal efficiency of $\mathrm{Cd}$ increased from $77 \%$ to $79 \%$ with the increasing of contact time from $48 \mathrm{~h}$ to $144 \mathrm{~h}$. At pH 6, the removal efficiency of $\mathrm{Cd}$ (II) decreased from $72 \%$ to $56 \%$ with the increasing of initial concentration from 10 to $40 \mu \mathrm{g} / \mathrm{ml}$ and the removal efficiency increased from $79 \%$ to $81 \%$ with the increase of contact time from $48 \mathrm{~h}$ to $144 \mathrm{~h}$. The removal efficiency of $\mathrm{Cd}$ decreased from about $81 \%$ to $78 \%$ with the increase in initial concentration of $\mathrm{Cd}$ from 10 to $40 \mu \mathrm{g} / \mathrm{ml}$, while that of $\mathrm{Cd}$ increased from $72 \%$ to $77 \%$ slightly with the increase of pH 5 .

\section{Discussion}

Sorption is a method of mass transfer by which a material is moved from the liquid phase to a solid's surface and/or chemical interactions are attached to the substance. Sorption may be used as a low-cost alternative to traditional processes due to the wide surface area, high sorption potential and surface reactivity of sorbents being the suitable candidates for environmental regeneration, restoration and recovery of heavy metals (Congeevaram et al., 2007; Bestawy et al., 2013; Andreazza et al., 2011). Biosorption is a passive adsorption mechanism in which heavy metal is oxidative and in cell surface elements, ions are passively adsorbed to that of (Ayangbenro and Babalola, 2017; Shamim, 2018).

Bacterial symbiosis with leguminous plants offers tolerance against various stresses such as drought, salinity, heavy metals and other contaminants to the host plant wherein remediation is primarily achieved through the processes of biosorption or bioaccumulation (Limcharoensuk et al., 2015). Interstingely, the root nodulating $E$. adhaerens has been reported in biosorption of polychlorinated phenyls (Chen et al., 2015) but heavy metals bioaccumulation and sorption by microorganisms such as rhizobia is still in infancy (Oves et al., 2017).

First we, identified the heavy metal tolerant bacterial strain E. adhaerens KS23 and optimised conditions (pH and temperature) for maximum bioaccumulation taking into account the toxic effects of heavy metals and the biosorption ability of soil microbiota. Strain $E$. adhaerens KS23, a characterized bacteria from contaminated soils despite the presence of Cd (II) in excess of permissible limits (Saha et al., 2010) proved to be tolerant to heavy metals toxicity upto $184.5 \mu \mathrm{g} / \mathrm{ml}$ as evident by MIC values (Figure 1). Many factors, such as metal-ion concentration, biomass volume, contact time and pH value, etc., affect the removal efficiency of heavy metals by microorganisms (Bueno et al., 2008). It can be used to design a study, build experiments, and models study the influence of such factors on one or more dependent variables in order to clarify the variables' connection and selecting the optimal experimental conditions (Homayoonfal et al., 2015).

Kotoky et al., (2019) elaborated that Glutathione-S-transferase (GST) activity is primarily responsible for heavy metal tolerance in bacteria, therefore, an increase in activity indicates positive biosorption of heavy metals by bacteria thus contributing to bioremediation. Similarly, the 9.7 fold increase in GST activity in our study reveals effective heavy metal biosorption by $E$. adhaerens KS23. The appropriateness of temperature directly affects the role of microbial adsorbents, so it is a very important factor affecting the removal efficiency of cadmium adsorption. In a similar study by Zhang et al. (2013), upto 80 \% of $\mathrm{Hg}^{2+}$ was adsorbed by Gst $_{p m}{ }^{-4}$ from Proteus mirabilis when the $\mathrm{pH}$ was adjusted to 6.0 as also evidenced in $E$. adhaerens $\mathrm{KS}_{2} 3$ wherein, the maximum adsorption of $\mathrm{Cd}^{2+}{\text { by } \mathrm{Gst}_{a}}$ mediated from $E$. adhaerens $\mathrm{KS} 23$ was $81 \%$, respectively.

The quantity of transition metals accumulated within cells, due to the variable in genetic makeup of microbe and external physiological conditions, such as $\mathrm{pH}$ and temperature. In this regard, Banerjee et al. (2015) also observed that the maximum metal accumulation occurrs at $\mathrm{pH} 6$ and temperature $35^{\circ} \mathrm{C}$, which were ideal conditions for microbial growth and development. In our analysis, E. adhaerens KS23 accumulated the most metal at pH 6 and $30{ }^{\circ} \mathrm{C}$ significantly (Table 4). Similar to our study on Ensifer adhaerens and Pisum sativum L. demonstrated a fascinating phenomenon, proving beneficial and defensive and majorly reduced heavy metal stress in polluted soil. Khan et al. (2009) found that legume symbiotic rhizobia can act as a heavy metal chelator as well as a plant growth promoter in a contaminated field. 
From the soil analysis, heavy metals contaminants in soil confirmed that the soil was contaminated by the heavy metals due to leaching from the nearby dumpsite and vehicular emissions. In such circumstances, high temperature influence the growth of the microorganism by involvement of the catalytic reactions. The decrease in the removal efficiency was adversely affected to that of high temperature. In such situations, the functional groups and the fluidity of the cell membrane showed maximum biosorption efficiency was recorded at 25 ${ }^{\circ} \mathrm{C}$ by $\mathrm{E}$. adhaerens KS23. These observations get support from previous studies; $\mathrm{pH}$ is the most important factor affecting the biosorption capacity of microorganisms for heavy-metals (Choińska-Pulit et al., 2018). The change of pH can not only affect the nature of cell surface charge, the protonation or deprotonation of functional groups and the permeability of cell membranes, but also the valence of cadmium in aqueous solutions (Kazy et al., 2006; Liu et al., 2016) but role of other factors cannot be ruled out.

The removal efficiency due to $E$. adhaerens gradually decreased corresponding to the increasing cadmium concentration. Previous studies had shown that at low ion concentration, the ratio of the moles of metal ions to the available surface area was low, and a large number of binding sites remained in the solutions (Leyva-Ramos et al., 2005). On the contrary, at high concentrations of Cd (II), lack of sufficient free binding sites adversely affected the removal efficiency (Erkaya et al., 2014). Therefore, the center point of Cd (II) concentration chosen for further course of investigators and it was $25 \mu \mathrm{g} / \mathrm{ml}$ and yielded maximum biosorption by E. adhaerens KS 23 . On the other hand, high initial concentrations of metal ions could adversely affect microbial biomass (Kazy et al., 2006).

The 3D surface plots are graphical diagrams of regression equations showing two factors, while all other factors maintained at fixed levels (Hadiani et al., 2018). In fact, one of the important parameters that affected the adsorption of soluble metal ions by various biosorbants is the $\mathrm{pH}$ of the biosorption medium (Farhan and Khadom, 2018; Isam et al., 2019). The pH changes had an effect on the competition of binding sites and the activity of functional groups on the microbial cell wall (Javed et al., 2019). Further, the potential of cationic metal biosorption increased with rising $\mathrm{pH}$ of the sorption system upto $\mathrm{pH}$ 7, but not in a linear relationship being decreased on further rise in $\mathrm{pH}$ 8. At very high pH and temperature, it is likely to precipitate of metal complexes (Guibaud et al., 2006), which also affected biosorption. Therefore, an increase in biosorption efficiency of root-nodulating bacteria E. adhaerens KS23 have dual role to play, thus alleviating stress caused by heavy metal Cd (II) to the soil and increases the growth and productivity of $P$. sativum L.

\section{Conclusion}

The study revealed an eco-friendly, cost-effective sorbent for heavy metals was demonstrated using RSM based approach. The PGP microsymbiont bacterium Ensifer adhaerens KS23 demonstrated a high potential for cadmium (II) adsorption. In this analysis, the effects of contact time, $\mathrm{pH}$, temperature, dosage of biomass and initial concentration of $\mathrm{Cd}$ (II) on its adsorption by $E$. adhaerens KS23 were studied in single factor experiments by using RSM-based BBD in optimizing cadmium adsorption. A significant factor in the biosorption process has also been considered as a relationship between contact time and $\mathrm{pH}$ value. ANOVA analysis model $\left(p<0.02, r^{2}\right.$ $=73.35 \%$ ) showed a sufficient consistency between the observed and predicted values. Efficiency of $E$. adhaerens KS23 under optimal conditions accounted for $81.249 \%$. Cd (II) removal efficiency demonstrated the model's accuracy. The influence of temperature have a little impact on the efficiency of removal, which is of great practical importance, particularly in adverse conditions for the subsequent application of biological adsorbents to the natural environment. This study offers a potent and effective tool in the form of a bacteria ( $E$. adhaerens). This has prompted to investigate the potentials of enhancing the biosorption of Cd (II) heavy metal accumulation in soil used for recovery of its fertility for rasising crops especially in those regions where heavy metal pollution is a matter of consideration. Thus, the benefit of combining heavy-metals tolerant E. adhaerens KS23 may play a key role in host adaptation to a changing soil environment in contaminated soil.

\section{Declarations}

\section{Author's Contributions}

PK executed the experiments and drafted the manuscript. SK and DKM planned, corrected and finalized the manuscript before submission. RCD checked and finalised the manuscript before submission.

\section{Acknowledgments}

DKM acknowledge the UGC- BSR faculty fellowship for financial support provided during the course of investigations. The authors are thankful to the Head, Department of Botany and Microbiology, Gurukula Kangri (Deemed to be) University, Haridwar (India).

\section{Conflict of Interest}


The authors declare that there are no conflicts of interest.

\section{References}

Al-Garni, S. M. (2005). Biosorption of lead by Gram-negative capsulated and non-capsulated bacteria. Water Saf, 31(3), 345-350

Andreazza, A. C., Berk, M. F., Kapczinski, Dean, O. M., Giorlando, F., Maes, M., and Malhi, G. S. (2011). Pathways underlying neuroprogression in bipolar disorder: focus on inflammation, oxidative stress and neurotrophic factors. Neurosci Biobehav Rev, 35(3), 804-817

Ayangbenro, A. S., and Babalola, O. O. (2017). A new strategy for heavy metal polluted environments: a review of microbial biosorbents. Int $j$ Env Res Pub Health, 14(1), 94

Banerjee S, Gothalwal R, Sahu PK, and Sao S. (2015) Microbial observation in bioaccumulation of heavy metals from the ash dyke of thermal power plants of Chhatisgarh, India. Adv. Biosci. Biotechnol, 6:131-8

Bestawy, E. E., Helmy, S., Hussien, H., Fahmy, M., and Amer, R. (2013). Bioremediation of heavy metal-contaminated effluent using optimized activated sludge bacteria. Appl.water sci., 3(1), 181-192

Bueno, B. Y. M., Torem, M. L., Molina, F. A. L. M. S., and De Mesquita, L. M. S. (2008). Biosorption of lead (II), chromium (III) and copper (II) by R. opacus: Equilibrium and kinetic studies. Miner. eng., 21(1), 65-75

Chen, X., Wei, Y., Li, H., Liang, M., and Xu, L. (2015). Biosorption and biodegradation mechanisms of trichlorobiphenyl by Ensifer adhaerens. China Environ Sci, 35(5), 1423-1428

Chi, Y., Huang, Y., Wang, J., Chen, X., Chu, S., Hayat, K. and Zhang, D. (2020). Two plant growth promoting bacterial Bacillus strains possess different mechanisms in adsorption and resistance to cadmium. Sci Tot Env, 741, 140422

Choińska-Pulit, A., Sobolczyk-Bednarek, J., and Łaba, W. (2018). Optimization of copper, lead and cadmium biosorption onto newly isolated bacterium using a Box-Behnken design. Ecotoxicol. Environ. saf., 149, 275-283

Congeevaram, S., Dhanarani, S., Park, J., Dexilin, M., and Thamaraiselvi, K. (2007). Biosorption of chromium and nickel by heavy metal resistant fungal and bacterial isolates. J Haz. Mat., 146(1-2), 270-277

Dubey, R. C., and Maheshwari, D. K. (2012). Practical Microbiology. S. Chand Pvt. Limited, New Delhi, India

Edulamudi, P., Zakkula, V., Vanga, U. R., and Konada, V. M. (2019). Copper effect on photosynthetic performance, symbiotic efficiency and biosorption of rhizobia associated with Horse gram [Macrotyloma uniflorum (Lam.) Verdc.]. Cuba J Agri Sci, 53(4)

Erkaya, I. A., Arica, M. Y., Akbulut, A., and Bayramoglu, G. (2014). Biosorption of uranium (VI) by free and entrapped Chlamydomonas reinhardtii: kinetic, equilibrium and thermodynamic studies. J. Radioanal Nucl. Chem., 299(3), 1993-2003

Farhan, S. N., Khadom, A. A., and Karim, A. M. E. A. (2018). Copper and lead ions removal from aqueous solution using MgO. Appl. Chem Eng., 1(4)

Guibaud, G., van Hullebusch, E., and Bordas, F. (2006). Lead and cadmium biosorption by extracellular polymeric substances (EPS) extracted from activated sludges: $\mathrm{pH}$-sorption edge tests and mathematical equilibrium modelling. Chemosphere, 64(11), 1955-1962

Habig, W. H., Pabst, M. J., Fleischner, G., Gatmaitan, Z., Arias, I. M., and Jakoby, W. B. (1974). The identity of glutathione S-transferase B with ligandin, a major binding protein of liver. Proc. Nat. Acad. Sci., 71(10), 3879-3882

Hadiani, M. R., Darani, K. K., Rahimifard, N., and Younesi, H. (2018). Biosorption of low concentration levels of Lead (II) and Cadmium (II) from aqueous solution by Saccharomyces cerevisiae: Response surface methodology. Biocatal. Agric. Biotechnol., 15, 25-34

Homayoonfal, M., Khodaiyan, F., and Mousavi, M. (2015). Modelling and optimising of physicochemical features of walnut-oil beverage emulsions by implementation of response surface methodology: Effect of preparation conditions on emulsion stability. Food chem., 174, $649-659$ 
Isam, M., Baloo, L., Kutty, S. R. M., and Yavari, S. (2019). Optimisation and Modelling of Pb (II) and Cu (II) Biosorption onto Red Algae (Gracilaria changii) by Using Response Surface Methodology. Water, 11(11), 2325

Javed, M. T., Tanwir, K., Akram, M. S., Shahid, M., Niazi, N. K., and Lindberg, S. (2019). Phytoremediation of cadmium-polluted water/sediment by aquatic macrophytes: role of plant-induced pH changes. In Cadmium Toxicity and Tolerance in Plants (pp. 495-529). Academic Press

Katiyar, P., Dubey, R. C., and Maheshwari, D. K. (2021). ACC deaminase-producing Ensifer adhaerens KS23 enhances proximate nutrient of Pisum sativum L. cultivated in high altitude. Arch. Microbiol, 1-10

Kazy, S. K., Das, S. K., and Sar, P. (2006). Lanthanum biosorption by a Pseudomonas sp.: equilibrium studies and chemical characterization. J. Ind. Microbiol. Biot., 33(9), 773-783

Khan MS, Zaidi A, Wani PA, and Oves M. (2009). Role of plant growth promoting rhi- zobacteria in the remediation of metal contaminated soils. Environ.Chem. Lett., 7(1):1-19

Kotoky, R., Nath, S., Maheshwari, D. K., and Pandey, P. (2019). Cadmium resistant plant growth promoting rhizobacteria Serratia marcescens S2I7 associated with the growth promotion of rice plant. Env. Sust., 2(2), 135-144

Kumar, S., Stecher, G., Li, M., Knyaz, C., and Tamura, K. (2018). MEGA X: molecular evolutionary genetics analysis across computing platforms. Mol. Biol. Evol, 35(6), 1547-1549

Leyva-Ramos, R., Bernal-Jacome, L. A., and Acosta-Rodriguez, I. (2005). Adsorption of cadmium (II) from aqueous solution on natural and oxidized corncob. Sep. Purif. Technol., 45(1), 41-49

Li, C., Yang, X., Xu, Y., Li, L., and Wang, Y. (2018). Cadmium detoxification induced by salt stress improves cadmium tolerance of multistress-tolerant Pichia kudriavzevii. Env Pollut, 242, 845-854

Limcharoensuk, T., Sooksawat, N., Sumarnrote, A., Awutpet, T., Kruatrachue, M., Pokethitiyook, P., and Auesukaree, C. (2015). Bioaccumulation and biosorption of $\mathrm{Cd}^{2+}$ and $\mathrm{Zn}^{2+}$ by bacteria isolated from a zinc mine in Thailand. Ecotoxicol. Environ. saf., 122, 322330

Nagata, S., Yamaji, K., Nomura, N., and Ishimoto, H. (2015). Root endophytes enhance stress-tolerance of Cicuta virosa L. growing in a mining pond of eastern Japan. Plant sp. biol., 30(2), 116-125

Oves, M., Khan, M. S., and Qari, H. A. (2017). Ensifer adhaerens for heavy metal bioaccumulation, biosorption, and phosphate solubilization under metal stress condition. J Taiwan Inst Chem Eng, 80, 540-552

Qasemi, M., Zarei, A., Afsharnia, M., Salehi, R., Allahdadi, M., and Farhang, M. (2018). Data on cadmium removal from synthetic aqueous solution using garbage ash. Data brief, 20, 1115-1123

Radu, T., and Diamond, D. (2009). Comparison of soil pollution concentrations determined using AAS and portable XRF techniques. J. Haz. Mat., 171(1-3), 1168-1171

Raymond H. Myers, Douglas C. Montgomery, Christine M. and Anderson-Cook, "Response Surface Methodology: Process and Product Optimization Using Designed Experiments," John Wiley and Sons Inc; 3 edition (January 14, 2009)

Saha, J. K., Panwar, N. R., and Singh, M. V. (2010). Determination of lead and cadmium concentration limits in agricultural soil and municipal solid waste compost through an approach of zero tolerance to food contamination. Env. Mon. Assess. 168(1), 397-406

Sathvika, T., Soni, A., Sharma, K., Praneeth, M., Mudaliyar, M., Rajesh, V., and Rajesh, N. (2018). Potential application of Saccharomyces cerevisiae and Rhizobium immobilized in multi walled carbon nanotubes to adsorb hexavalent chromium. Sci Rep, 8(1), 1-13

Stylianou, M. A., Kollia, D., Haralambous, K. J., Inglezakis, V. J., Moustakas, K. G., and Loizidou, M. D. (2007). Effect of acid treatment on the removal of heavy metals from sewage sludge. Desalin., 215(1-3), 73-81

Wang, J., and Chen, C. (2009). Biosorbents for heavy metals removal and their future. Biotechnol. Adv., 27(2), 195-226 
Wang, Q., Li, Q., Lin, Y., Hou, Y., Deng, Z., Liu, W., and Xia, Z. (2020). Biochemical and genetic basis of cadmium biosorption by Enterobacter ludwigii LY6, isolated from industrial contaminated soil. Env Poll, 264, 114637

Wang, Y., Jiang, X., Li, K., Wu, M., Zhang, R., Zhang, L., and Chen, G. (2014). Photosynthetic responses of Oryza sativa L. seedlings to cadmium stress: physiological, biochemical and ultrastructural analyses. Biometals, 27(2), 389-401

Weller, D. M., and Cook, R. J. (1983). Suppression of take-all of wheat by seed treatments with fluorescent pseudomonads. Phytopathol., 73(3), 463-469

Yu, H. Y., Liu, C., Zhu, J., Li, F., Deng, D. M., Wang, Q., and Liu, C. (2016). Cadmium availability in rice paddy fields from a mining area: the effects of soil properties highlighting iron fractions and pH value. Environ. Pollut., 209, 38-45

Zhang, W., Yin, K., Li, B., and Chen, L. (2013). A glutathione S-transferase from Proteus mirabilis involved in heavy metal resistance and its potential application in removal of $\mathrm{Hg}^{2+}$. J. Haz. Mat., 261, 646-652

\section{Tables}

Table 1: Concentration of heavy metals in soil before and after treatment

\begin{tabular}{|c|c|c|c|c|c|c|c|c|c|c|}
\hline $\begin{array}{l}\text { S. } \\
\text { No. }\end{array}$ & Sample $^{a}$ & $\mathrm{~Pb}^{\mathrm{b}}$ & $\mathrm{Cd}$ & Co & $\mathrm{Cr}$ & $\mathrm{Mn}$ & $\mathrm{Ni}$ & $\mathrm{Cu}$ & $\mathrm{Zn}$ & $\mathrm{Fe}$ \\
\hline 1. & $\begin{array}{l}\text { Control } \\
\text { (Sterilised } \\
\text { soil) }\end{array}$ & $14.3 \pm 1.3$ & $0.25 \pm 0.03$ & $4.56 \pm 0.31$ & $11.2 \pm 1.4$ & $128 \pm 11$ & $39.5 \pm 2.98$ & $6.97 \pm 1.2$ & $32 \pm 1.7$ & $7245 \pm 142$ \\
\hline 2. & $\begin{array}{l}\text { Pre- } \\
\text { sowing } \\
\text { Soil }\end{array}$ & $45.6 \pm 2.7$ & $4.84 \pm 0.41$ & $13.5 \pm 0.98$ & $32.98 \pm 1.6$ & $278 \pm 28$ & $62.3 \pm 3.6$ & $36.54 \pm 2.65$ & $54 \pm 4.9$ & $9546 \pm 426$ \\
\hline 3. & $\begin{array}{l}\text { Post- } \\
\text { harvest } \\
\text { Soil }\end{array}$ & $24.6 \pm 1.4$ & $1.62 \pm 0.24$ & $5.23 \pm 0.39$ & $18.6 \pm 0.2$ & $121 \pm 22$ & $42.3 \pm 3.26$ & $21.2 \pm 1.2$ & $29 \pm 5.4$ & $7485 \pm 340$ \\
\hline
\end{tabular}

${ }^{a} n=3$

${ }^{b}$ Concentration of heavy metals $\mathrm{Pb}, \mathrm{Cd}, \mathrm{Co}, \mathrm{Cr}, \mathrm{Mn}$ and $\mathrm{Ni}(\mu \mathrm{g} / \mathrm{kg})$ in soil sample and all other heavy metals (mg/ $\mathrm{kg}$ )

Table 2: The experimental variables range and level in this study:

\begin{tabular}{|llll|}
\hline Variables & Temperature ${ }^{\circ} \mathrm{C}$ & $\mathrm{pH}$ & Initial Cd (II) Concentration $(\mu \mathrm{g} / \mathrm{ml})$ \\
\hline-1 & 15 & 5 & 10 \\
\hline 0 & 30 & 6 & 25 \\
+1 & 45 & 7 & 40 \\
\hline
\end{tabular}

Table 3: The Box-Behnken experiment design of response surface methodology (RSM) with three independent variables 


\begin{tabular}{|llllll|}
\hline Run order & A (Temperature) & B (pH) & C (Initial concentration) & $\begin{array}{l}\text { Actual removal } \\
(\%)\end{array}$ & Predicted response (\%) \\
\hline 1 & 30 & 6 & 25 & 64.564 & 63.156 \\
\hline 2 & 30 & 6 & 25 & 71.254 & 70.486 \\
\hline 3 & 45 & 6 & 10 & 72.369 & 73.472 \\
\hline 4 & 45 & 5 & 25 & 58.483 & 60.198 \\
\hline 5 & 30 & 5 & 40 & 76.264 & 74.256 \\
\hline 6 & 45 & 6 & 40 & 56.216 & 57.489 \\
\hline 7 & 30 & 7 & 40 & 78.459 & 78.564 \\
\hline 8 & 15 & 6 & 10 & 58.452 & 59.521 \\
\hline 9 & 15 & 7 & 25 & 76.954 & 77.413 \\
\hline 10 & 30 & 6 & 25 & 81.249 & 79.512 \\
\hline 11 & 30 & 6 & 25 & 69.423 & 63.471 \\
\hline 12 & 15 & 6 & 40 & 66.421 & 64.24 \\
\hline 13 & 30 & 5 & 10 & 74.955 & 75.214 \\
\hline 14 & 30 & 6 & 25 & 77.889 & 79.215 \\
\hline 15 & 30 & 7 & 10 & 79.416 & 78.124 \\
\hline 16 & 15 & 5 & 25 & 66.238 & 68.256 \\
\hline 17 & 45 & 7 & 25 & 71.048 & 73.412 \\
\hline
\end{tabular}

Table 4: Analysis of Variance for quadratic model of Response surface

\begin{tabular}{|lllllll|}
\hline Source & Sum of Squares & df & Mean Square & F-value & p-value & \\
\hline Model & 716.56 & 9 & 79.62 & 26.54 & 0.0164 & Significant \\
\hline A-Temperature & 12.37 & 1 & 12.37 & 0.3326 & 0.5822 & \\
\hline B-pH & 112.03 & 1 & 112.03 & 3.01 & 0.1262 & \\
\hline C-Initial concentration & 7.67 & 1 & 7.67 & 0.2061 & 0.6635 & \\
\hline AB & 0.8547 & 1 & 0.8547 & 0.0230 & 0.8838 & \\
\hline AC & 145.47 & 1 & 145.47 & 3.91 & 0.0885 & \\
\hline BC & 1.28 & 1 & 1.28 & 0.0345 & 0.8579 & \\
\hline A & 364.41 & 1 & 364.41 & 9.80 & 0.0166 & \\
\hline B & 89.33 & 1 & 89.33 & 2.40 & 0.1651 & \\
\hline$C^{2}$ & 0.1862 & 1 & 0.1862 & 0.0050 & 0.9456 & \\
\hline Residual & 260.37 & 7 & 37.20 & & & \\
\hline Lack of Fit & 81.38 & 3 & 27.13 & 0.6063 & 0.6450 & not significant \\
\hline Pure Error & 178.98 & 4 & 44.75 & & & \\
\hline Cor Total & 976.93 & 16 & & & & \\
\hline
\end{tabular}

$\mathrm{R}^{2}=0.7335$; 
Adjusted $\mathrm{R}^{2}=0.8908$;

Predicted $\mathrm{R}^{2}=0.8192$

\section{Figures}

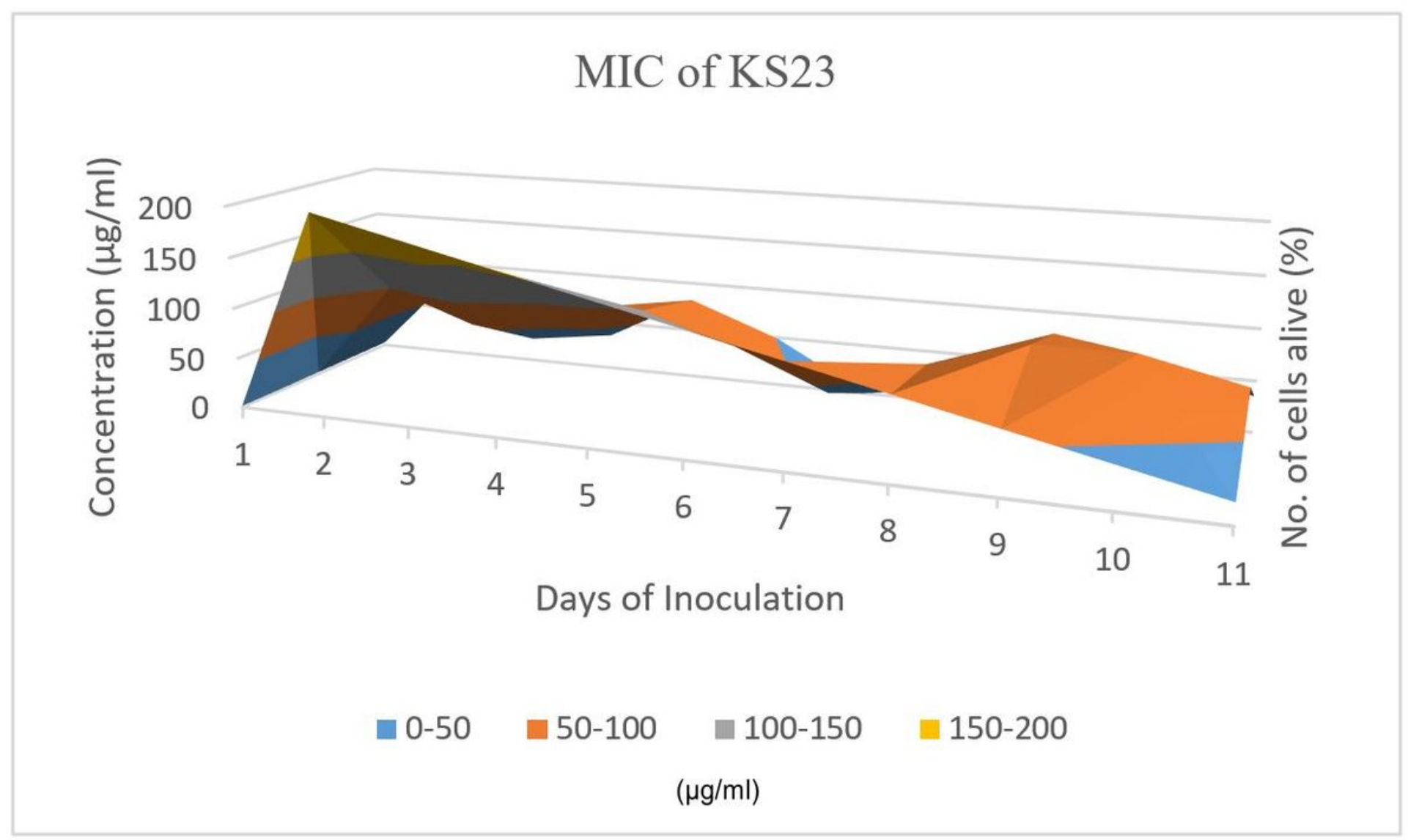

\section{Figure 1}

Determination of Minimum Inhibitory Concentration $(\mu \mathrm{g} / \mathrm{ml})$ of cadmium due to E. adhaerens KS23. 


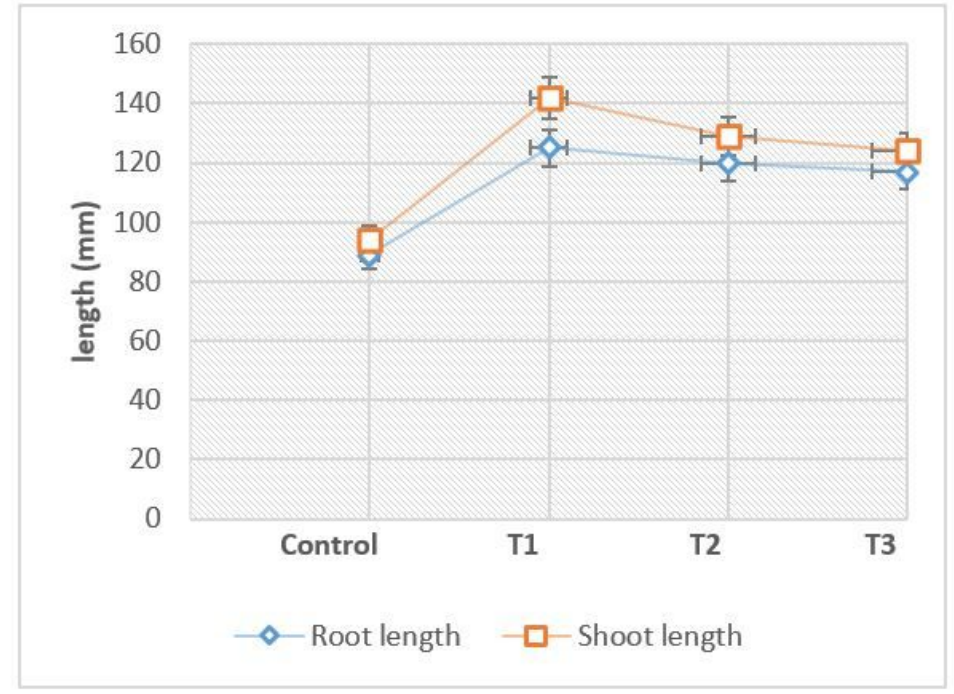

(a)
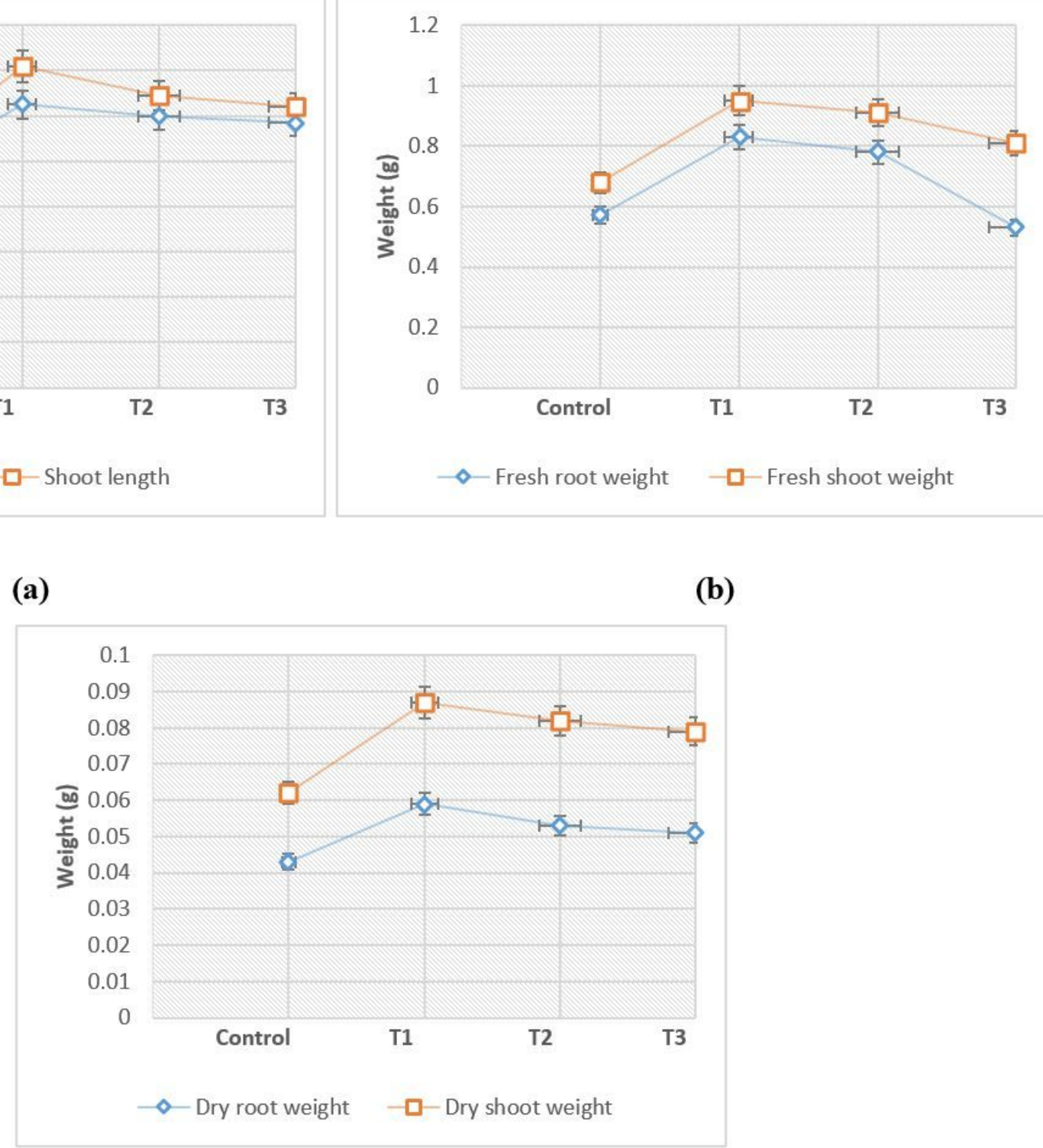

(c)

(b)

Figure 2

Effect of treatments on vegetative parameters after 30 DAS (a) root and shoot length; (b) root and shoot fresh weight; (c) root and shoot dry weight. 


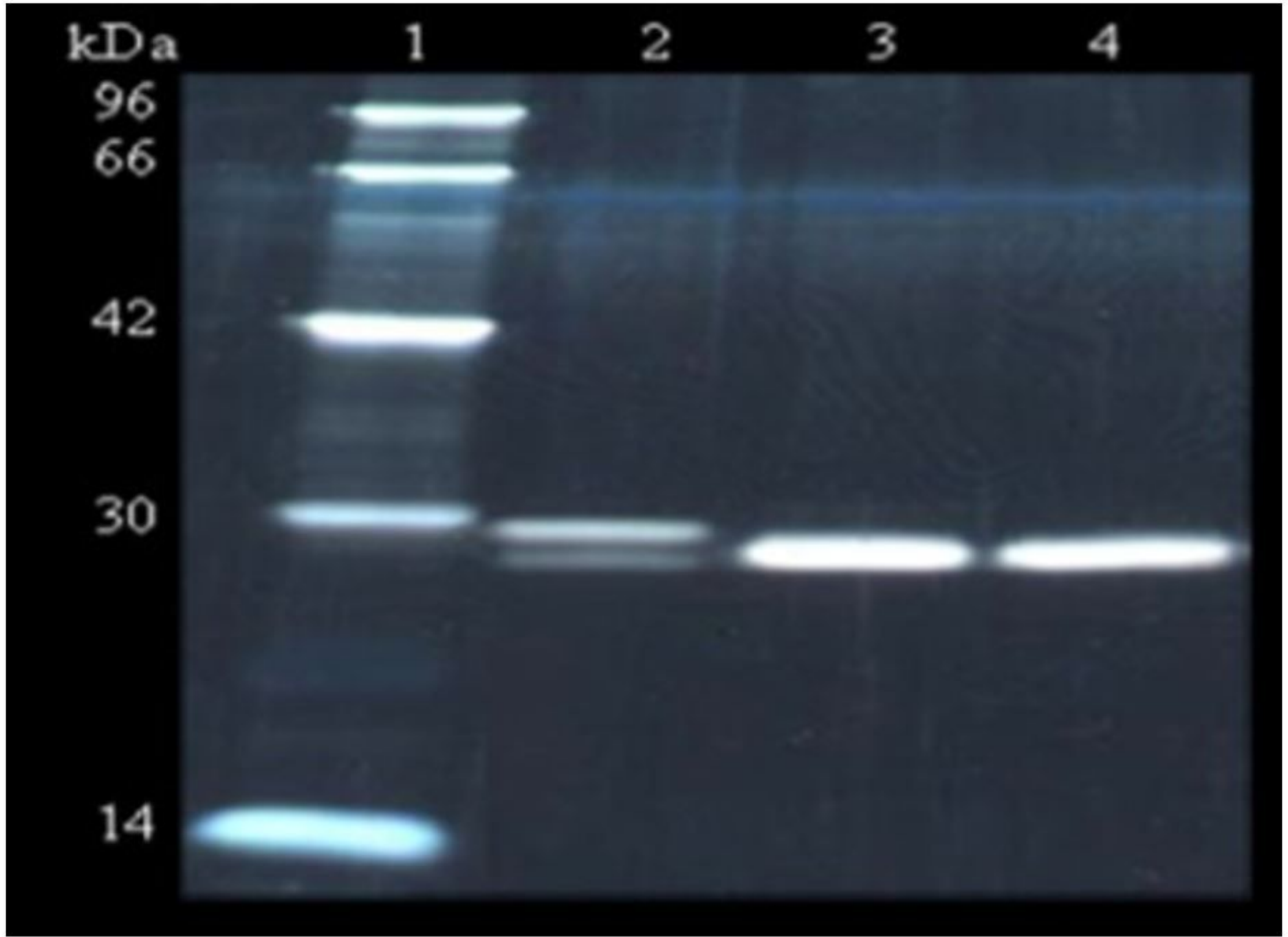

\section{Figure 3}

Gel electrophoresis image of purified GSTa from the selected isolates (A). Lane 1, Molecular weight marker; Lane 2: KS09; Lane 3: KS23; Lane 4: KR16 


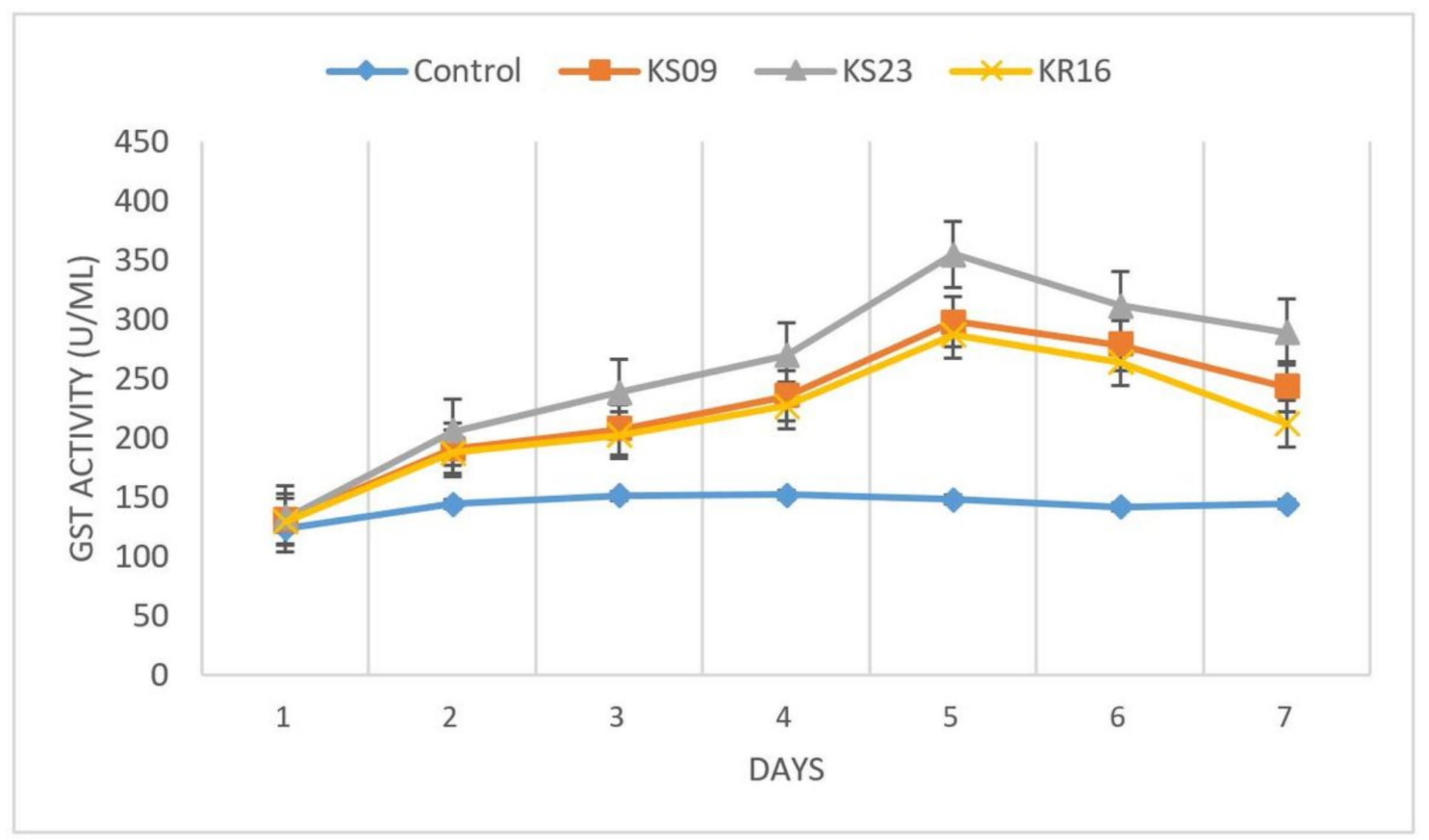

\section{Figure 4}

Increase in GST activity of selected isolates under Cd stress increase in initial concentration of Cd from 10 to $40 \mu \mathrm{g} / \mathrm{ml}$, while that of Cd increased from $72 \%$ to $77 \%$ slightly with the increase of $\mathrm{pH} 5$. 

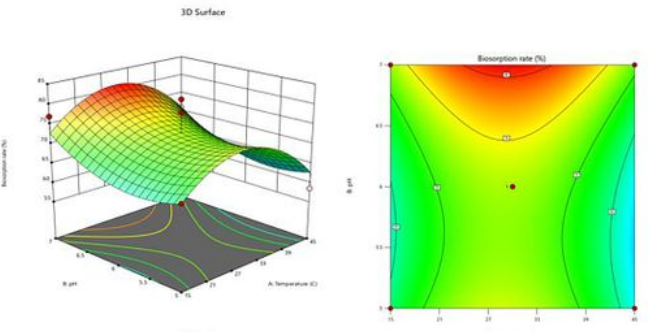

$=$
$0=$
$\cdots=$
$\cdots=$

(b)
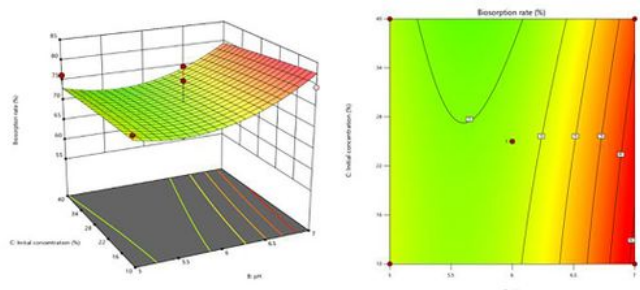

$=$

(c)
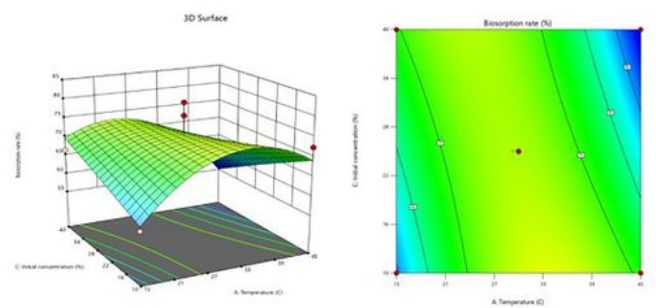

$=$

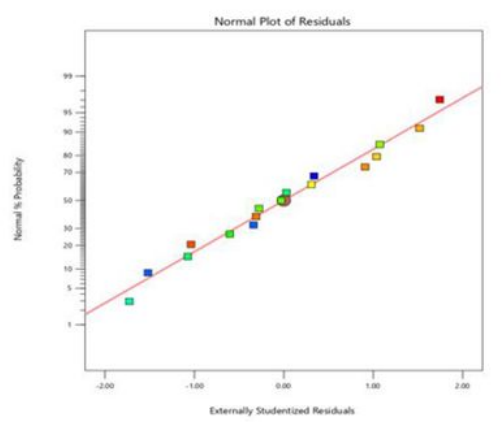

(d)

\section{Figure 5}

3D surface and Contour plots of (a) temperature and $\mathrm{pH}$; (b) temperature and initial concentration; (c) initial concentration and $\mathrm{pH}$; (d) Normal plot of residuals showing percentage normal probability forming a nearly linear pattern of variable. The residuals were externally studentized using the mean square error based on the estimated model

\section{Supplementary Files}

This is a list of supplementary files associated with this preprint. Click to download.

- Graphicalabstract.docx

- Supplementary.docx 